\title{
Transmission of solar radiation through clouds on melting glaciers: a comparison of parameterizations and their impact on melt modelling
}

\author{
Francesca PELLICCIOTTI, Thomas RASCHLE, Thomas HUERLIMANN, \\ Marco CARENZO, Paolo BURLANDO
}

\author{
Institute of Enviromental Engineering, Federal Institute of Technology, ETH Hönggerberg, CH-8093 Zürich, Switzerland \\ E-mail: pellicciotti@ifu.baug.ethz.ch
}

\begin{abstract}
We explore the robustness and transferability of parameterizations of cloud radiative forcing used in glacier melt models at two sites in the Swiss Alps. We also look at the rationale behind some of the most commonly used approaches, and explore the relationship between cloud transmittance and several standard meteorological variables. The $\mathbf{2} \mathbf{m}$ air-temperature diurnal range is the best predictor of variations in cloud transmittance. However, linear and exponential parameterizations can only explain $\mathbf{3 0 - 5 0} \%$ of the observed variance in computed cloud transmittance factors. We examine the impact of modelled cloud transmittance factors on both solar radiation and ablation rates computed with an enhanced temperature-index model. The melt model performance decreases when modelled radiation is used, the reduction being due to an underestimation of incoming solar radiation on clear-sky days. The model works well under overcast conditions. We also seek alternatives to the use of in situ ground data. However, outputs from an atmospheric model (2.2 km horizontal resolution) do not seem to provide an alternative to the parameterizations of cloud radiative forcing based on observations of air temperature at glacier automatic weather stations. Conversely, the correct definition of overcast conditions is important.
\end{abstract}

\section{INTRODUCTION}

Net shortwave radiation is a key component of the energy balance at the glacier-atmosphere interface, and has been shown to be the major source of energy for melting of snow and ice across glaciers and latitudes (Arnold and others, 1996; Pellicciotti and others, 2008; Mölg and others, 2009). In recent decades, models of solar radiation under clear-sky conditions have been substantially advanced by including in various degrees the effect of topography, in particular of shading and reflection from the surrounding slopes, and of atmospheric transmittance (e.g. Corripio, 2003b; Anslow and others, 2008; Mölg and others, 2009). Inclusion of cloud cover, however, is still problematic because of the complex interaction between clouds and the solar radiation beam and the scarcity of cloud-cover observations for high mountainous sites (Zhang and others, 1996; Pfister and others, 2003). Clouds affect the incoming shortwave radiation by both reducing the shortwave radiation incident to a surface and changing its wavelength composition (making it relatively richer in visible wavelengths) (Zhang and others, 1996; Van den Broeke and others, 2004). The average net effect is a reduction of the incoming shortwave radiation reaching the surface (Zhang and others, 1996).

An approach that has often been adopted in numerical models of snow- and ice melt is to compute so-called 'cloud factors', defined as the ratio of measured and modelled clear-sky solar radiation (Greuell and others, 1997; Klok and Oerlemans, 2002; Pfister and others, 2003; Fitzpatrick and Warren, 2005; Garen and Marks, 2005). They are also known as 'raw cloud transmittance' (Fitzpatrick and Warren, 2005) and have been used extensively in atmospheric studies to represent cloud radiative properties or forcing (Thornton and Running, 1999; Pfister and others, 2003; Fitzpatrick and others, 2004; Fitzpatrick and Warren, 2005).
If shortwave radiation measurements are available, such as for studies at the point scale, there is no need to model incoming solar radiation. For distributed models of glacier ablation, however, measured solar radiation needs to be extrapolated to or simulated for the gridcells. Cloud factors are then used as modifiers of clear-sky modelled radiation (Klok and Oerlemans, 2002; Anslow and others, 2008; Mölg and others, 2009). For modelling approaches that rely only on measured air temperature, such as the temperature-index model in its various formulations (Hock, 2005; Pellicciotti and others, 2005), this approach can be taken a step further by seeking a relationship between the computed cloud factors and the daily temperature range as the independent variable. Once this relationship is established, it can be used in distributed models to compute the daily cloud factor from observations of air temperature at synoptic weather stations (Pellicciotti and others, 2005). In this way, cloud factors can be used to derive parameterizations that depend on variables more routinely available than solar radiation, such as air temperature.

There have been a number of attempts to develop a straightforward method to relate the attenuation provided by cloudy skies to readily available datasets that define the nature of the clouds and, in particular, to standard meteorological variables (Frederick and Steele, 1995). Several works have highlighted the strong relationship between variations in the diurnal range of air temperature $(\Delta T)$ and variations in a variable representing the radiative forcing of the clouds. $\Delta T$ shows a clear correlation with changes in cloud cover because of the decrease in maximum surface temperature and increase in minimum temperature occurring under overcast conditions. The maximum temperature would in fact decrease when there are more clouds because of less downward solar radiation during daytime, when the 


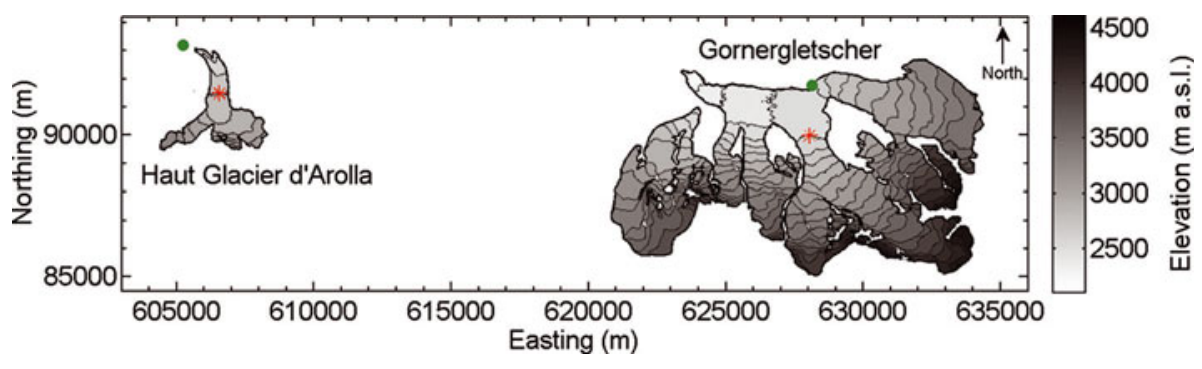

Fig. 1. Map of Haut Glacier d'Arolla and Gornergletscher with the positions of the AWSs on (red) and off (green) glacier used in this paper.

maximum would most likely occur. Clouds would also act to raise the minimum air temperature because an increase in clouds would produce a larger incoming longwave radiation flux (Campbell and Vonder Haar, 1997).

The aims of this work are to: (1) test the cloud-cover parameterization developed by Pellicciotti and others (2005) at two alpine locations where shortwave radiation data are available; (2) explore alternative parameterizations of cloud cover; and (3) assess the impact of the parameterizations on the modelling of glacier melt. In doing so, we make use of meteorological variables collected at automatic weather station (AWS) sites located at Haut Glacier d'Arolla and Gornergletscher, both in the southeastern Swiss Alps (Fig. 1). To identify alternative methods of taking into account the influence of cloud cover on the shortwave radiation balance, we also compare our results with modelled solar radiation and melt simulations obtained using output data from the atmospheric Consortium for Small-Scale Modelling (COSMO) model of the Swiss Meteorological Office.

\section{STUDY SITES AND DATA}

\subsection{Study sites}

Haut Glacier d'Arolla (referred to here as Arolla) and Gornergletscher (referred to here as Gorner) differ in terms of topographical characteristics, areal extent and altitudinal range (see Table 1), but are located in an area of similar general climatic features.

\subsection{Meteorological and topographical data}

For each glacier, we used meteorological data from one offand one on-glacier AWS (Fig. 1). On Haut Glacier d'Arolla, we used data from the so-called lowest AWS of the stations described in detail by Pellicciotti and others (2005). Records are available for the 2001 and 2006 seasons (Table 2). On Gornergletscher, an AWS was set up at about $2600 \mathrm{~m}$ a.s.I. in both 2005 and 2006. The period of functioning was shorter in 2005 (Table 2). The glacier AWSs recorded data for a period of $5 \mathrm{~min}$ (average of $5 \mathrm{~s}$ measurements) of ventilated

Table 1. Characteristics of the two glaciers where AWSs were installed for this work. $H$ is elevation

\begin{tabular}{lrccc}
\hline Glacier & Area & $\begin{array}{c}H \text { range } \\
\text { ma.s.l. }\end{array}$ & $\begin{array}{c}\text { Mean } H \\
\text { ma.s.l. }\end{array}$ & $\begin{array}{c}\text { Length } \\
\mathrm{km}\end{array}$ \\
\hline Arolla & 6.3 & $2550-3500$ & 3029 & 4 \\
Gorner & 57.5 & $2150-4500$ & 3221 & 14 \\
\hline
\end{tabular}

air temperature $\left({ }^{\circ} \mathrm{C}\right)$, relative humidity (\%), incoming and reflected shortwave radiation $\left(\mathrm{W} \mathrm{m}^{-2}\right)$, wind speed $\left(\mathrm{m} \mathrm{s}^{-1}\right)$ and direction $\left({ }^{\circ}\right.$ ). All sensors were set up on an arm fixed to a tripod that sat on the glacier surface and was allowed to sink with the melting of the glacier surface, thus maintaining a nominal height of $2 \mathrm{~m}$ between the surface and sensors. Measurements of incoming and reflected shortwave radiation were therefore made parallel to the surface following Sicart and others (2001), Greuell and Genthon (2004) and Pellicciotti and others (2005).

A permanent station situated at about $900 \mathrm{~m}$ from Arolla terminus (Fig. 1) has been recording hourly values of ventilated air temperature, among other variables, since 2001. A permanent off-glacier AWS measuring ventilated air temperature and relative humidity was in use on Gornergletscher in 2005 and 2006 (Fig. 1). Observations of air temperature recorded at these two off-glacier stations are used together with data from the glacier stations for analysis of cloud-cover variations and development of the cloud transmittance factor parameterization.

Station characteristics and period of functioning are listed in Table 2. Four main datasets are used: Arolla 2001, Arolla 2006, Gorner 2005 and Gorner 2006. The Haut Glacier $\mathrm{d}^{\prime}$ Arolla dataset is described in detail by Pellicciotti and others (2005), while the Gornergletscher measurements are discussed by Carenzo and others (2009). All meteorological data were aggregated into hourly values before being used for the analysis.

The solar radiation model described below requires a digital elevation model (DEM) of the glacier and surrounding area for computation of the direct incoming shortwave radiation and interaction of the sunbeam with the local topography, in particular to take into account the shading effect. We used a $10 \mathrm{~m}$ DEM of Arolla derived from aerial photographs taken in 1999 (Pellicciotti, 2004) and a $25 \mathrm{~m}$ DEM of Gornergletscher, also derived from aerial photographs (Carenzo and others, 2009).

\subsection{COSMO data}

The non-hydrostatic limited-area atmospheric model COSMO-7 (http://www.meteoschweiz.admin.ch/) provides detailed climate forecasts for the entire Alpine region at a grid spacing of $2.2 \mathrm{~km}$. We used data extracted from a reanalysis (i.e. continuous integration with continuous assimilation of observations) that started on 1 January 2000 and ended on 31 December 2002, with lateral boundary conditions taken from the global European Centre for Medium-Range Weather Forecasts (ECMWF) model (http://www.ecmwf. int/). COSMO uses terrain-following coordinates and 45 vertical layers of variable height above sea level, hence a variable resolution of layers (increasing from the surface 
from 12.6 to $2235.4 \mathrm{~m})$. It employs the radiative transfer scheme by Ritter and Geleyn (1992), which is based on the solution of the $\delta$-two stream version of the radiative transfer equation incorporating the effect of scattering, absorption and emission by cloud droplets, aerosols and gases in each part of the spectrum (Ritter and Geleyn, 1992). We used the modelled $2 \mathrm{~m}$ air temperature, incoming shortwave radiation and total cloud cover for the grid of latitude $45^{\circ} 968^{\prime} \mathrm{N}$ and longitude $7^{\circ} 532^{\prime} \mathrm{E}$, covering most of Haut Glacier d'Arolla. Mean elevation of the gridcell is 2906 ma.s.l. (similar to the mean elevation of the glacier tongue) and the grid surface type is ice. The solar radiation is with respect to a horizontal surface, and shading by the surrounding topography is not accounted for.

Figure 2 shows hourly incoming shortwave radiation measured at the lowest AWS on Arolla together with hourly incoming shortwave radiation modelled by COSMO for the period 17-27 July 2001. Radiation from the limited-area climate model is higher than the observed radiation by $49.4 \mathrm{~W} \mathrm{~m}^{-2}$ on average over the common period of record, most frequently with overestimation in the central part of the day (Fig. 2). The model is able to correctly reproduce cloudy conditions on the two overcast days 20 and 24 July (Fig. 2).

Modelled air temperature agrees quite well with the $2 \mathrm{~m}$ air temperature at the lowest station on Arolla, but is too low when compared with the temperature time series at the proglacial station. The diurnal amplitude, however, is more like that of the off-glacier temperature record, so the damping effect of the $0^{\circ} \mathrm{C}$ glacier surface on the temperature variability does not seem to be completely included in the model.

\section{METHODS}

\subsection{Solar radiation model}

Clear-sky incoming solar radiation is computed using a nonparametric model based on lqbal (1983) and further modified by Bird and Hulstrom (1981) to best reproduce the output of the rigorous solar radiation model SOLTRAN. This was shown to be one of the best available approaches in the comparative study by Niemelä and others (2001), outperforming three physically based radiation schemes used in numerical weather prediction models. The model computes the transmittance through the atmosphere after attenuation due to Rayleigh scattering, uniformly mixed gases, water vapour, aerosols and ozone. To derive the terrain parameters and solar position from the DEM and the interaction between the solar radiation and the topography, we use the vectorial algebra approach proposed by Corripio (2003b). In the following, we report only the main equations and refer the reader to Corripio (2003b) for details.

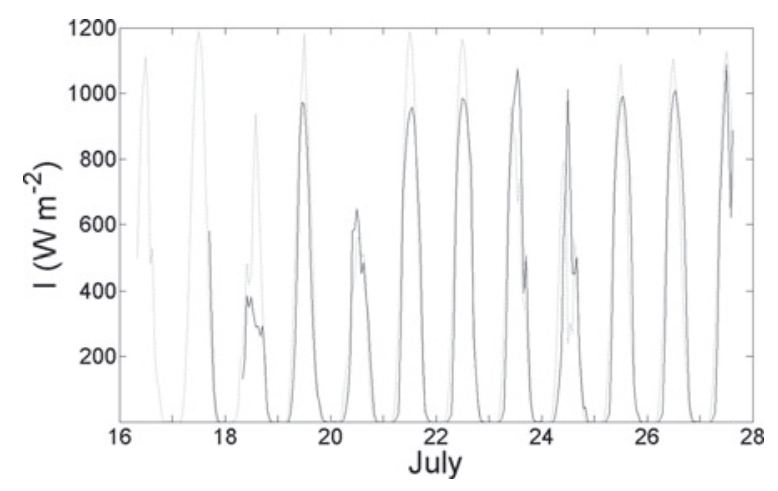

Fig. 2. Incoming shortwave radiation measured at the lowest AWS on Arolla (solid curve) and modelled by the COSMO limited-area climate model in the gridcell corresponding to Arolla (dotted curve) for the period 17-27 July 2001.

The fraction of light intercepted by the inclined surface is proportional to the cosine of the angle between the normal to the surface and the sun's rays. Hillshading is computed by checking the projection of a gridcell over the plane perpendicular to the solar rays, following the direction of the sun (Corripio, 2003b). The sky-view factor, $\Psi$, defined as the hemispherical fraction of unobstructed sky visible from any point, is important in the evaluation of incoming diffuse radiation $\left(I_{\mathrm{d}}\right) . \Psi$ is computed as the ratio of the projected surface of the visible part of the hemisphere to the area of the whole hemisphere of unitary radius. Clear-sky potential incoming shortwave radiation $I_{\mathrm{POT}}$ is computed as

$$
I_{\mathrm{POT}}=I_{\mathrm{n}} \cos \Phi+I_{\mathrm{d}} \Psi,
$$

where $I_{\mathrm{n}}$ is the direct normal irradiance and $\Phi$ is the angle between the normal to the surface and the sun's rays.

$I_{\mathrm{n}}$ is calculated as

$$
I_{\mathrm{n}}=0.9751 I_{0}\left(\tau_{\mathrm{r}} \tau_{\mathrm{o}} \tau_{\mathrm{g}} \tau_{\mathrm{w}} \tau_{\mathrm{a}}+\beta(z)\right),
$$

where the factor 0.9751 is the ratio of the extraterrestrial irradiance in the spectral interval $0.3-3.0 \mu \mathrm{m}$ (used by the SOLTRAN model) to the solar constant $I_{\mathrm{SC}}$ (Bird and Hulstrom, 1981; Corripio, 2003a);

$$
I_{0}=I_{\mathrm{sC}}\left(\frac{R_{0}}{R}\right)^{2}
$$

is the extraterrestrial solar radiation or solar constant corrected for the eccentricity of the Earth's orbit, where $R_{0}$ is the actual Sun-Earth distance and $R$ is the mean Sun-Earth distance; and the $\tau$ functions are transmittance functions for Rayleigh scattering $\left(\tau_{\mathrm{r}}\right)$ and transmittance due to ozone $\left(\tau_{\mathrm{o}}\right)$,

\begin{tabular}{|c|c|c|c|c|c|}
\hline Glacier & $\begin{array}{c}\text { Elevation } \\
\text { ma.s.l. }\end{array}$ & Latitude & Longitude & Period of functioning & Year \\
\hline Arolla & 2830 & $7.52^{\circ} \mathrm{E}$ & $45.97^{\circ} \mathrm{N}$ & $\begin{array}{c}30 \text { May-21 Jun, } 18 \text { Jul-11 Sep } \\
26 \text { May-30 Sep }\end{array}$ & $\begin{array}{l}2001 \\
2006\end{array}$ \\
\hline Gorner & 2604 & $7.80^{\circ} \mathrm{E}$ & $45.96^{\circ} \mathrm{N}$ & $\begin{array}{l}4 \text { Jun-15 Sep } \\
22 \text { May-11 Sep }\end{array}$ & $\begin{array}{l}2005 \\
2006\end{array}$ \\
\hline
\end{tabular}

Table 2. Characteristics and period of functioning of the glacier AWSs at the study sites Haut Glacier d'Arolla (2001 and 2006) and Gornergletscher (2005 and 2006) 
uniformly mixed gases $\left(\tau_{\mathrm{g}}\right)$, water vapour $\left(\tau_{\mathrm{w}}\right)$ and aerosols $\left(\tau_{\mathrm{a}}\right)$. The total transmittance of the atmosphere is thus accounted for as the product of single transmittance. $\beta(z)$ is a correction term for altitude, introduced following Bintanja (1996) to take into account the increase of transmittance with altitude:

$$
\beta(z)=2.2 \times 10^{-5} z \text { for } z \leq 3000 \mathrm{~m},
$$

where $z$ is altitude. While $\beta(z)$ is strongly linear up to $3000 \mathrm{~m}$, it is fairly constant and equal to $2.2 \times 10^{-5} \mathrm{~m}^{-1}$ after $3000 \mathrm{~m}$. The computation of the individual transmittance follows Bird and Hulstrom (1981) and requires knowledge of the relative optical air mass, $m_{r}$. Iqbal (1983) suggested a formula which approximates values from a transmittance model:

$$
m_{\mathrm{r}}=\frac{1.0}{\cos \theta+0.15\left(93.885-\theta_{\mathrm{d}}\right)^{-1.253}},
$$

where $\theta_{\mathrm{d}}$ is the zenith angle in degrees, or $\theta(180 / 2 \pi)$. This approximation is for standard pressure, and can be corrected for local pressure $p_{z}$ :

$$
m_{\mathrm{a}}=m_{\mathrm{r}} \frac{p_{z}}{1013.25},
$$

where $p_{z}$ is computed as explained by Corripio (2003a).

Transmittance by ozone is calculated as

$$
\begin{aligned}
\tau_{0}= & 1.0-\left\{0.1611 / m_{\mathrm{r}}\left[1.0+139.48 / m_{\mathrm{r}}\right]^{-0.3035}\right. \\
& \left.-0.002715 / m_{\mathrm{r}}\left[1.0+0.044 / m_{\mathrm{r}}+0.0003\left(I m_{\mathrm{r}}\right)^{2}\right]^{-1}\right\},
\end{aligned}
$$

where $I$ is the vertical ozone layer thickness $(\mathrm{cm})$, assumed to be $0.35 \mathrm{~cm}$ according to data from the Total Ozone Mapping Spectrometer Earth Probe (TOMS-EP 2001). Transmittance by uniformly mixed gases is computed as

$$
\tau_{\mathrm{g}}=\mathrm{e}^{-0.0127 m_{\mathrm{a}}^{0.26}} \text {. }
$$

Transmittance by water vapour is:

$$
\begin{aligned}
\tau_{\mathrm{w}}= & 1.0-2.4959 w_{\mathrm{p}} m_{\mathrm{r}} \\
\cdot & \cdot\left[\left(1.0+79.034 w_{\mathrm{p}} m_{\mathrm{r}}\right)^{0.6828}+6.385 w_{\mathrm{p}} m_{\mathrm{r}}\right]^{-1,}
\end{aligned}
$$

where $w_{p}$ is precipitable water $(\mathrm{cm})$. This is calculated using an empirical equation proposed by Prata (1996):

$$
w_{\mathrm{p}}=46.5 \frac{\mathrm{e}_{0}}{T_{\mathrm{a}}},
$$

where $T_{\mathrm{a}}$ is the screen-level air temperature $(\mathrm{K})$ and $e_{0}$ is the actual vapour pressure, defined as $e_{0}=e^{*} \times \mathrm{RH}$ where $\mathrm{RH}$ is relative humidity within the range $0.1-1.0$ and $e^{*}$ is saturated vapour pressure computed using Lowe's (1977) polynomials.

The transmittance by aerosols is not easy to determine when direct information on atmospheric turbidity is not available (Corripio, 2003a). Here it is computed as a function of visibility $\nu(\mathrm{km})$ which was estimated.

The diffuse component of solar radiation is also computed following lqbal (1983). The total diffuse radiation $I_{\mathrm{d}}$ is the sum of the Rayleigh-scattered diffuse irradiance $I_{\mathrm{dr}}$, the aerosol-scattered diffuse irradiance $I_{\mathrm{da}}$ and the diffuse irradiance from multiple reflections between the Earth and the atmosphere $I_{\mathrm{dm}}$ (Corripio, 2003a):

$$
I_{\mathrm{d}}=I_{\mathrm{dr}}+I_{\mathrm{da}}+I_{\mathrm{dm}} \text {. }
$$

The Rayleigh-scattered diffuse irradiance is given by

$$
I_{\mathrm{dr}}=0.79 I_{0} \cos \theta \tau_{0} \tau_{\mathrm{g}} \tau_{\mathrm{w}} \tau_{\mathrm{aa}} \frac{0.5\left(1.0-\tau_{\mathrm{r}}\right)}{\left(1.0-m_{\mathrm{a}}+m_{\mathrm{a}}^{1.02}\right)},
$$

where $\tau_{\mathrm{aa}}$ is the transmittance of direct radiation due to aerosol absorptance. The aerosol-scattered diffuse irradiance is

$$
I_{\mathrm{da}}=0.79 I_{0} \cos \theta \tau_{0} \tau_{\mathrm{g}} \tau_{\mathrm{w}} \tau_{\mathrm{aa}} F_{c} \frac{\left(1.0-\tau_{\mathrm{as}}\right)}{\left(1.0-m_{\mathrm{a}}+m_{\mathrm{a}}^{1.02}\right)},
$$

where $\tau_{\mathrm{as}}=\tau_{\mathrm{a}} / \tau_{\mathrm{aa}}$ and $F_{\mathrm{C}}$ is the fraction of forward scattering to total scattering (assumed 0.84 after Iqbal (1983) as no information on aerosol was available in this study).

The diffuse irradiance from multiple reflections between the Earth and the atmosphere is calculated as:

$$
I_{\mathrm{dm}}=\frac{\left(I_{\mathrm{n}} \cos \theta+I_{\mathrm{dr}}+I_{\mathrm{da}}\right) \alpha_{\mathrm{g}} \alpha_{\mathrm{a}}^{\prime}}{\left(1.0-\alpha_{\mathrm{g}} \alpha_{\mathrm{a}}^{\prime}\right)},
$$

where $\alpha_{\mathrm{g}}$ is the albedo of the ground which can be estimated from knowledge of the average snow cover around the point considered, as explained by Greuell and others (1997). Since this information is not available in our study, we assume a mean value of 0.4. $\alpha_{\mathrm{a}}^{\prime}$ is the atmospheric albedo, computed after lqbal (1983) as

$$
\alpha_{\mathrm{a}}^{\prime}=0.0685+\left(1.0-F_{\mathrm{C}}\right)\left(1.0-\tau_{\mathrm{as}}\right) .
$$

Finally, incoming shortwave radiation is obtained from $I_{\text {POT }}$ (Equation (1)) as

$$
I=I_{\text {POT }} c f,
$$

where $c f$ is a bulk transmittance due to clouds, referred to as the cloud transmittance factor in this paper.

\subsection{Computation of cloud transmittance factors}

Cloud transmittance factors within the range $0-1$ reduce the potential incoming solar radiation of a quantity that corresponds to the amount of clouds present and type of clouds (Zhang and others, 1996; Garen and Marks, 2005; Anslow and others, 2008). A value of $c f=1$ corresponds to a clear sky with no clouds, whereas $c f=0$ means that no shortwave radiation reaches the surface at all. In general, however, an overcast sky will have cf $>0$ (Garen and Marks, 2005; Anslow and others, 2008), with different values $>0$ for different cloud types. Anslow and others (2008), for instance, used $c f=0.4$ for completely cloudy conditions for South Cascade Glacier, Washington, USA.

Cloud transmittance factors are computed from hourly clear-sky radiation obtained with the model described above and from the measurements at the AWSs. Following Pellicciotti and others (2005), we first derive hourly cloud transmittance factors $c f_{\mathrm{H}}$ as the ratio of hourly measured $\left(I_{\text {MEAS }}\right.$ in $\mathrm{W} \mathrm{m}^{-2}$ ) to the hourly modelled incoming shortwave

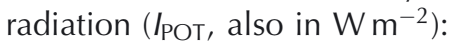

$$
c f_{\mathrm{H}}=\frac{I_{\mathrm{MEAS}}}{l_{\mathrm{POT}}}
$$

during the day, i.e. when the sun is above the horizon. We compute $c f_{\mathrm{H}}$ only when measured radiation is above a threshold of $120 \mathrm{~W} \mathrm{~m}^{-2}$, in order to exclude the low values of the early and late hours of the day, when measurements might be affected by errors and small differences between measured and modelled radiation can result in anomalous values of the cloud transmittance factors. During the night, when by definition the cloud transmittance factor cannot be 
Table 3. Mean value of air temperature $T$ and relative humidity $\mathrm{RH}$ at the glacier AWS and cumulated precipitation $P_{\mathrm{T}}$ at the off-glacier AWS

\begin{tabular}{|c|c|c|c|c|}
\hline$T(\%)$ & 2.2 & 3.7 & 5.1 & 5.2 \\
\hline $\mathrm{RH}(\%)$ & 73.2 & 75.6 & 64.5 & 60.5 \\
\hline$P_{\mathrm{T}}(\mathrm{mm}$ w.e. $)$ & 474 & 342 & 275 & 78 \\
\hline
\end{tabular}

computed, it is assumed to be constant and equal to the mean cloud transmittance factor of the previous afternoon.

We calculate hourly cloud transmittance factors because they permit derivation of weighted daily cloud transmittance factors. These are calculated by weighting each hourly $c f_{\mathrm{H}}$ according to the importance of the individual hourly $c f_{H} s$ to the total daily shortwave radiation flux.

The weighting factors are computed as the ratio of the incoming shortwave radiation in that hour to the daily total incoming shortwave radiation (Pellicciotti and others, 2005). In this way, each hourly $c f_{\mathrm{H}}$ is weighted according to the average theoretical incoming shortwave flux in that hour. In comparison to the arithmetic daily cloud transmittance factor, weighted daily cloud transmittance factors are much more dependent on conditions during the middle part of the day (which dominate the total shortwave receipts on a given day (Mölg and others, 2009)). This implies that the early and late parts of the day, which contribute little to shortwave flux, have little impact. In fact, if the early and late hours of the day are cloudy, this does not affect the total shortwave radiation input for that day very much. In the arithmetic mean daily cloud transmittance factor, all hourly $c f s$ are weighted equally, which seems wrong. We therefore suggest that the weighted cloud transmittance factor is a better indicator of the effects of clouds on shortwave radiation receipts.

\subsection{Cloud transmittance factor parameterization}

Following Bristow and Campbell (1984), Pellicciotti (2004) developed a cloud transmittance factor parameterization based on temperature variations during the day. This approach is based on wide evidence that clouds primarily affect the diurnal variations of $2 \mathrm{~m}$ air temperature (Dai and others, 1999) and that the daily temperature range can therefore be used as a predictor of changes in cloud radiative forcing (Bristow and Campbell, 1984; Tangborn, 1984).

Pellicciotti (2004) proposed the following parameterization:

$$
c f=a\left(1-\mathrm{e}^{-b \Delta T}\right)
$$

where $c f$ is the daily cloud transmittance factor discussed above, $\Delta T$ is the daily temperature range and $a$ and $b$ are two empirical coefficients computed from the data $(a=1$ and $b=0.1452$ ). Pellicciotti and others (2005) suggested an alternative linear parameterization,

$$
c f=a \Delta T+b,
$$

noticing that differences in the predictive skills of the two functions were very low. The optimized empirical coefficients of Equation (18) are $a=0.0600946$ and $b=0.3097$. In both cases, $\Delta T$ is computed from air-temperature data measured outside the glacier boundary layer, which are more representative of the synoptic air-temperature conditions (Pellicciotti and others, 2005). Temperature measured on the glacier is in fact affected by both the presence of a surface at melting point and by the glacier wind, which contribute to lower air temperature and smooth its diurnal fluctuations. This has already been demonstrated by Pellicciotti (2004) and Pellicciotti and others (2005), and was confirmed by our analysis.

For each site and season, we recalibrated Equations (17) and (18) with the cloud transmittance factors computed from measured and modelled incoming shortwave radiation. However, to identify alternative parameterizations, we analyze the relationship of computed cloud transmittance factors to all the meteorological variables available.

\subsection{Melt models}

Pellicciotti and others (2005) used the parameterization described in section 3.3 in an enhanced temperature-index (ETI) model (Pellicciotti and others, 2005, 2008; Carenzo and others, 2009) for simulations of hourly melt rates. These are computed as a function of air temperature and the shortwave radiation balance, i.e.

$$
M=\left\{\begin{array}{cc}
\operatorname{TF} T+\operatorname{SRF}(1-\alpha) I & T>T_{\mathrm{T}} \\
0 & T \leq T_{\mathrm{T}}
\end{array}\right.
$$

where $M$ is the hourly melt rate $\left(\mathrm{mm} w . e . \mathrm{h}^{-1}\right), T$ is air temperature $\left({ }^{\circ} \mathrm{C}\right), \alpha$ is albedo and $I$ is incoming shortwave radiation $\left(\mathrm{W} \mathrm{m}^{-2}\right)$. The temperature factor $\mathrm{TF}\left(\mathrm{mm} \mathrm{h}^{-1}{ }^{\circ} \mathrm{C}^{-1}\right)$ and the shortwave radiation factor SRF $\left(\mathrm{m}^{2} \mathrm{~mm} \mathrm{~W}^{-1} \mathrm{~h}^{-1}\right)$ are empirically determined and were calibrated against hourly energy-balance melt rates (Pellicciotti and others, 2005). The threshold temperature for melt to occur, $T_{\mathrm{T}}$, is $1^{\circ} \mathrm{C}$ (Pellicciotti and others, 2005). We do not recalibrate the model parameters, because they were calibrated at one of the locations investigated in this work and because they have been shown to be robust for Swiss Alpine glaciers (Carenzo and others, 2009).

An energy-balance model provides hourly values of computed ablation rate that we use to evaluate the melt rates simulated by the ETI model. The details of the energybalance model can be found in Pellicciotti and others (2008) and Carenzo and others (2009); they are not described here because the model has been extensively tested for Alpine sites (Carenzo and others, 2009; Pellicciotti and others, 2009).

\section{RESULTS}

\subsection{General meteorological conditions}

Figure 3 shows the daily mean values of air temperature and relative humidity at Arolla's lowest AWS in 2001 and 2006. Air temperature on the glacier is on average lower than at the off-glacier AWS because of the combined effect of the katabatic wind (Carenzo and others, 2009) and of the $0^{\circ} \mathrm{C}$ melting surface. There is clear anticorrelation between low air temperature and high relative humidity. The colder 

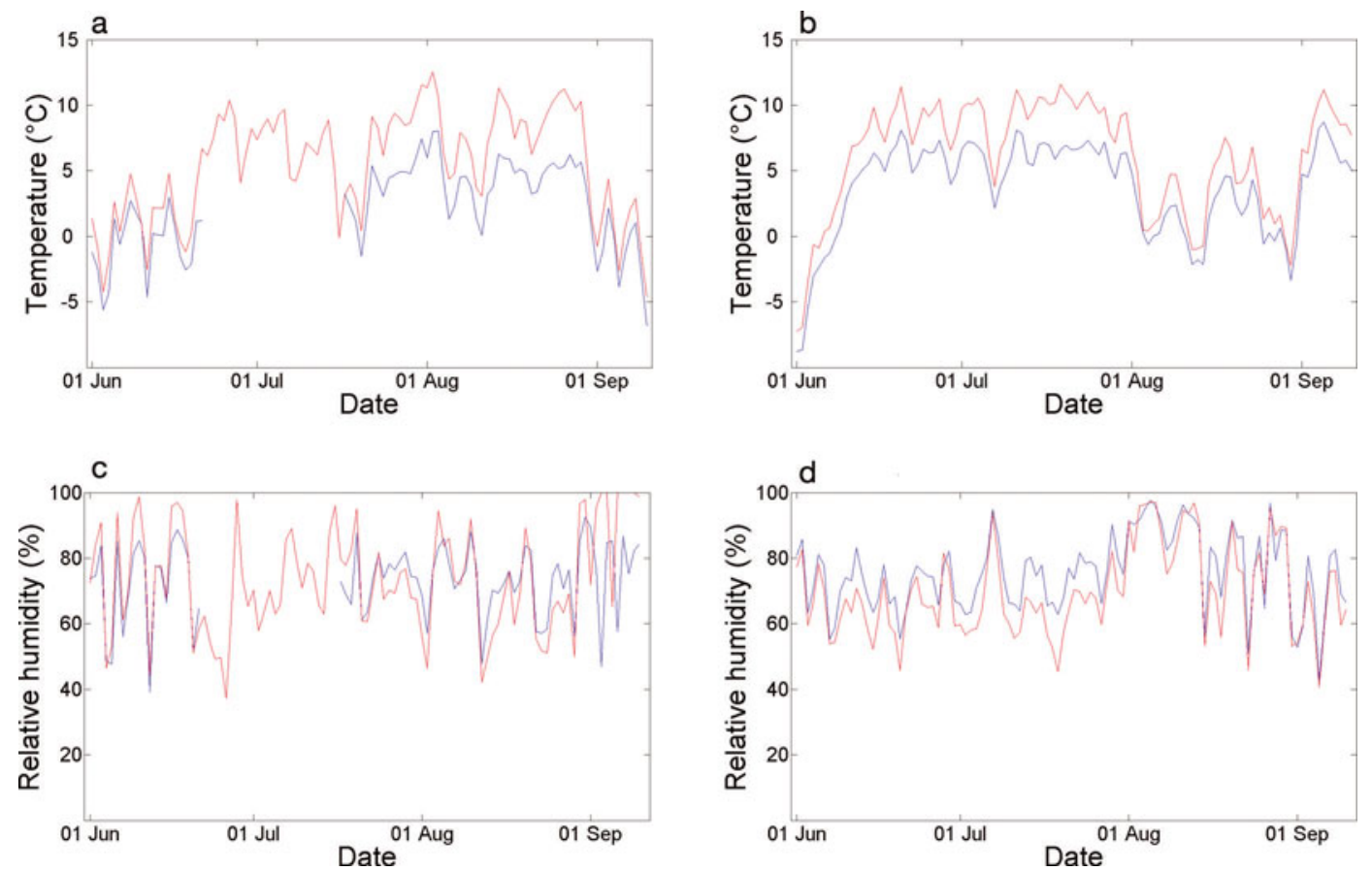

Fig. 3. Daily mean air temperature (a, b) and relative humidity (c, d) at Arolla 2001 (a, c) and Arolla 2006 (b, d) for the entire season. Blue indicates measurements on the glacier and red off the glacier.

season (2001) shows the highest record of precipitation (Table 3). The main difference between Arolla and Gorner is the amount of precipitation, which is much higher on Arolla (Table 3). Air temperature at Gorner AWS is higher than at Arolla (Table 3), but this is at least partly explained by the lower elevation of the Gorner AWS (Table 2).

\subsection{Solar radiation model}

Agreement between clear-sky modelled and measured hourly incoming shortwave radiation is high on average (Fig. 4). Comparison between modelled and measured radiation can be made only for clear-sky conditions. Differences in the simulated and observed time series also exist for clear-sky conditions, however, as indicated by the values of the efficiency criterion $R^{2}$ (Nash and Sutcliffe, 1970; Table 4), and are likely attributable to topographic effects.

Figure 5 shows the scatter plot of measured and modelled hourly incoming shortwave radiation at the two sites for the period of record for clear-sky conditions only. As expected,

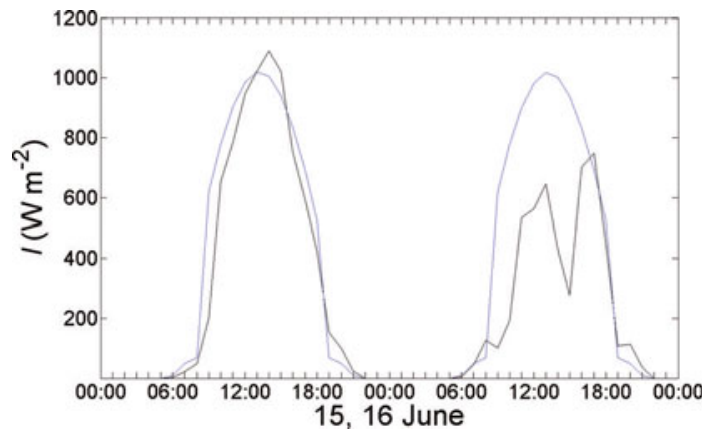

Fig. 4. Mean hourly incoming shortwave radiation $I$, modelled by the parametric clear-sky solar radiation model (blue) and measured (black) at Arolla lowest station on 15 and 16 June 2006. differences are higher early in the morning and later in the afternoon (blue and red dots). These are probably due to inaccuracies in the DEM and related uncertainty in the modelling of the interaction with the surrounding topography and of shading in particular. Discrepancies between modelled and measured radiation are relatively small at midday, when solar radiation is highest (Fig. 5). The mean difference over the period $1000-1600 \mathrm{~h}$ is $34 \mathrm{~W} \mathrm{~m}^{-2}$ for Arolla 2001, $6 \mathrm{~W} \mathrm{~m}^{-2}$ for Arolla 2006, $-20 \mathrm{~W} \mathrm{~m}^{-2}$ for Gorner 2005 (a mean negative value indicating that measured radiation is higher than the modelled) and $29 \mathrm{~W} \mathrm{~m}^{-2}$ for Gorner 2006.

At the sites considered in this study, the occurrence of cloudy conditions varies between 36.4\% for Gorner 2005 and $47.6 \%$ for Arolla (Carenzo and others, 2009), representing a large percentage of the total period of record and therefore affecting the accuracy of the solar radiation model. The values above and those plotted in Figure 5 are for clearsky days only. These were identified using an algorithm from Carenzo and others (2009). Given the large percentage of overcast conditions, however, the algorithm might have failed on a few days, especially those with low cloud cover

Table 4. Nash and Sutcliffe (1970) efficiency criterion $R^{2}$ for hourly modelled clear-sky solar radiation and measured incoming shortwave radiation at the four main sites

Site $R^{2}$

Entire record Clear-sky days

$\begin{array}{lll}\text { Arolla 2001 } & 0.605 & 0.947 \\ \text { Arolla 2006 } & 0.521 & 0.917 \\ \text { Gorner 2005 } & 0.681 & 0.953 \\ \text { Gorner 2006 } & 0.642 & 0.947\end{array}$



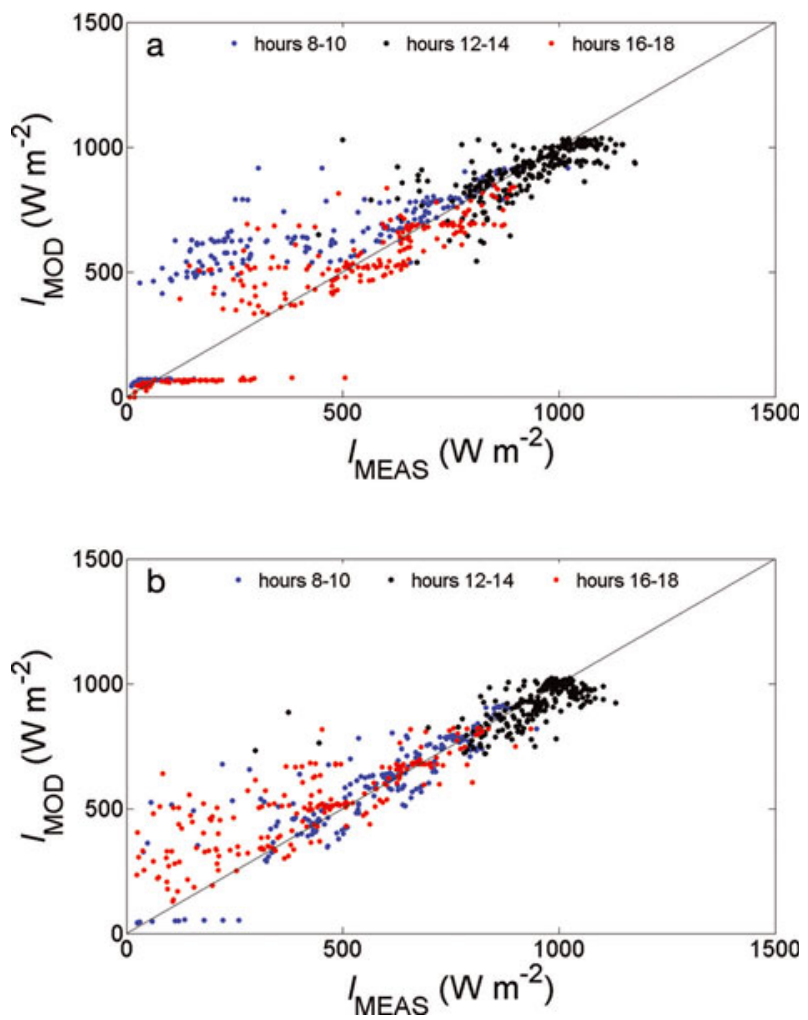

Fig. 5. Measured ( $I_{\text {MEAS }}$ ) versus modelled $\left(I_{\text {MOD }}\right)$ hourly incoming shortwave radiation for clear-sky days only over the period of record at the lowest AWS on (a) Arolla 2001 and 2006 and (b) Gorner 2005 and 2006. Colour codes indicate the hours between 800 and $1000 \mathrm{~h}$ (blue), 1200 and $1400 \mathrm{~h}$ (black) and 1600 and $1800 \mathrm{~h}$ (red). Also indicated is the $1: 1$ line.

concentrated over a few hours of the day. This might explain the two high peaks in the maximum difference, which are visible in both the Arolla and Gorner records.

Differences between measurements and estimated clearsky solar irradiance can be caused by low zenith angle, as pointed out by Pfister and others (2003). They restricted solar zenith angles to $75^{\circ}$ or less in the calculation of the ratio of
Table 5. Correlation coefficients between computed daily cloud transmittance factors and meteorological variables at the four main sites; all values are daily means. $I$ is incoming shortwave radiation and $\Delta T$ the daily temperature range

\begin{tabular}{lccc}
\hline Site & \multicolumn{1}{c}{$\Delta}$, & $\Delta T$ & Relative humidity \\
\hline Arolla 2001 & 0.799 & 0.680 & -0.366 \\
Arolla 2006 & 0.894 & 0.695 & -0.591 \\
Gorner 2005 & 0.871 & 0.572 & -0.640 \\
Gorner 2006 & 0.801 & 0.685 & -0.578 \\
\hline
\end{tabular}

measured to estimated clear-sky values, because the quality of the fit between the two quantities diminishes for lowelevation sun angles.

\subsection{Cloud transmittance factor: regression analysis}

Figure 6 shows the computed daily cloud transmittance factors $c f$ together with incoming solar radiation and relative humidity (at the glacier AWS) and the daily temperature range $\Delta T$ (at the off-glacier AWS) for Arolla 2006. As expected, cloud transmittance factors are clearly correlated with incoming shortwave radiation (Table 5).

Very low cloud transmittance factors, as on 1, 6 and 19 August, correspond at all sites to high relative humidity (Fig. 6), whereas the correspondence is less clear for higher $c f$. Correlation with the relative humidity record varies between -0.366 for Arolla 2001 and -0.640 for Gorner 2005. It is clear that the two variables are negatively correlated, since low cloud transmittance factors (corresponding to overcast conditions) are associated with high relative humidity. With the exception of Gorner 2005, correlation with $\Delta T$ is stronger (Table 5).

On average, daily cloud transmittance factors are higher on Gornergletscher (Table 6). The low average value for Arolla 2001 is associated with stronger variations over the seasons than at the other sites (standard deviation is higher; Table 6). Besides this, however, higher cloud transmittance factors on Gornergletscher reflect the drier conditions that

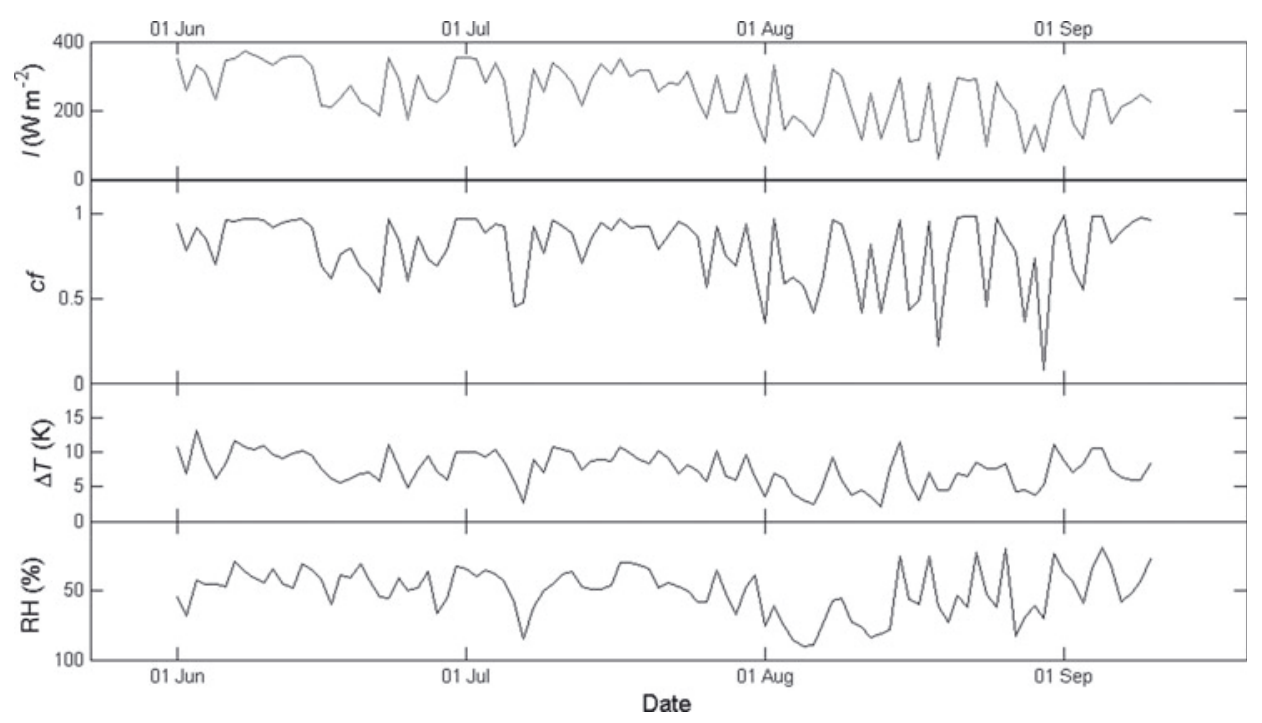

Fig. 6. Daily cloud transmittance factors, together with daily mean solar radiation I (glacier station), relative humidity $\mathrm{RH}$ (glacier station) and temperature range $\Delta T$ (off-glacier station) for Arolla 2006. 

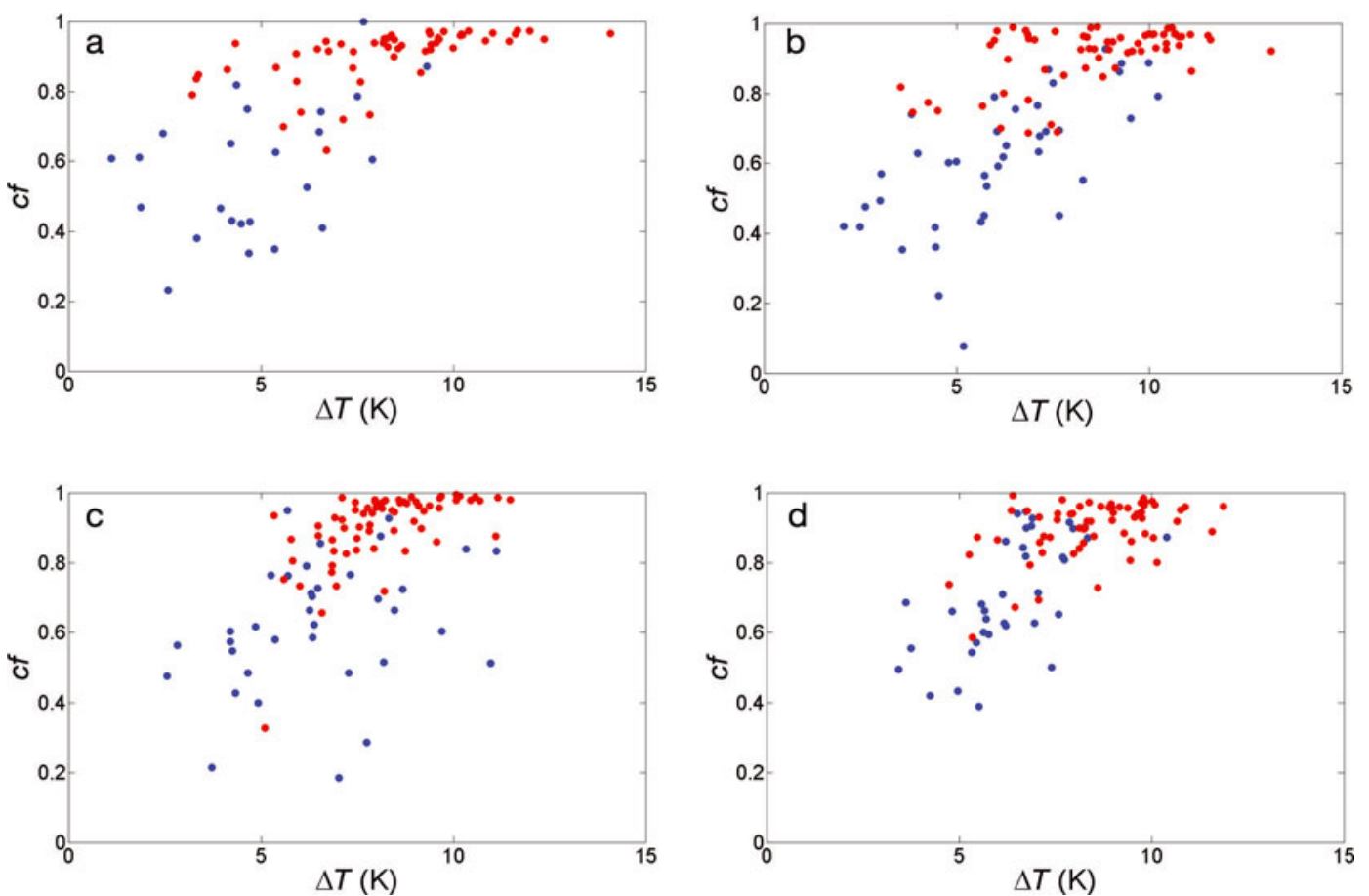

Fig. 7. Daily weighted cloud transmittance factors against daily temperature range at (a) Arolla 2001, (b) Arolla 2006, (c) Gorner 2005 and (d) Gorner 2006. Red dots indicate clear-sky days and blue dots cloudy days.

are typical of Gornergletscher and the surrounding area, despite the fact that the site is only tens of kilometres away from Arolla (Fig. 1).

For the cloud transmittance factors computed above, we examined correlation with the following variables at all sites: minimum, maximum and mean air temperature; minimum, maximum and mean relative humidity; and daily precipitation. For air temperature and temperature range, we correlated the daily cloud transmittance factor with both onand off-glacier values. Correlation is stronger with the daily temperature range at all sites (Fig. 7). Also relatively strong is the relationship with minimum relative humidity, in the sense that low values of minimum daily relative humidity seem to be good indicators of clear-sky conditions while the scatter in the relationship increases for low cf. Correlation with temperature measured at the glacier AWS is weaker, as shown already by Pellicciotti and others (2005) and discussed in detail by Pellicciotti (2004), because of the role of the glacier boundary layer in dampening diurnal temperature fluctuations (Greuell and Böhm, 1998; Klok and others, 2005; Pellicciotti and others, 2008). Interestingly, temperature alone (i.e. the minimum, maximum or mean values alone) are no indicator of cloud cover and correlation is very poor with time series both on- and

Table 6. Mean and standard deviation of computed daily cloud transmittance factors at the four main sites

\begin{tabular}{lcc}
\hline Glacier & Mean & Standard deviation \\
\hline Arolla 2001 & 0.794 & 0.199 \\
Arolla 2006 & 0.606 & 0.386 \\
Gorner 2005 & 0.815 & 0.187 \\
Gorner 2006 & 0.806 & 0.192 \\
\hline
\end{tabular}

off-glacier. Daily precipitation shows inverse correlation with $c f$, but the relationship has a rather large scatter. These relationships are consistent across sites and seasons, with only small variations in the shape of the clouds of points. The relationship of $c f$ to precipitation is anomalous on Gornergletscher in 2006, but this is likely explained by the very small amount of precipitation that fell in that season (mean value of $78 \mathrm{~mm}$ w.e. as compared to $275 \mathrm{~mm}$ w.e. in 2005 and 474 and 342 mm w.e. on Arolla in 2001 and 2006, respectively).

Similarly, large scatter is visible in the relationship with minimum relative humidity at Arolla in 2001. This might be explained by the large variation in the relative humidity data at the proglacial station (the dataset shows the largest variance of all datasets).

\subsection{Cloud transmittance factors: parameterizations}

Following Pellicciotti and others (2005), we tested the following regression equations: linear, polynomial, exponential and Gaussian (Table 7). Given the results in section 4.3 above, we performed a regression analysis using as independent variables both the daily temperature range and minimum relative humidity and used the coefficient of determination as an indication of the strength of the regression.

Figure 8 shows the best-fit regression functions for the pool of the four observation series together with the original data. Table 7 lists the coefficients of determination for the regression functions with daily temperature range as an independent variable for the four single datasets. The coefficients of determination for the regression with relative humidity are lower for all five models and are not reported here. The goodness-of-fit varies between 0.327 (Gornergletscher 2005, linear function) and 0.539 (Gornergletscher 2006, Gaussian function) (Table 7), and at all sites it is higher for the Gaussian and polynomial regression (as expected 
Table 7. Regression functions used in the regression analysis between the independent variable daily temperature range $\Delta T$ and the dependent variable daily cloud transmittance factor $c f$. Also shown are the values of the empirical coefficients obtained from best fits to data pooled from all four observation series. Columns 4-8 show the coefficients of determination for the regression equations for the four datasets and for the data pooled from all four observation series

\begin{tabular}{|c|c|c|c|c|c|c|c|}
\hline Function & $\Delta T$ & Coefficients & Arolla 2001 & Arolla 2006 & Gorner 2005 & Gorner 2006 & All \\
\hline Linear & $c f=a \Delta T+b$ & $0.0542,0.399$ & 0.423 & 0.484 & 0.327 & 0.469 & 0.427 \\
\hline Polynomial & $c f=a \Delta T^{2}+b \Delta T+c$ & $\begin{array}{c}-0.00397 \\
0.112,0.208\end{array}$ & 0.470 & 0.501 & 0.379 & 0.533 & 0.447 \\
\hline Exponential 1 & $c f=a[1-\exp (-b \Delta T)]$ & $1.094,0.189$ & 0.396 & 0.493 & 0.365 & 0.515 & 0.431 \\
\hline Exponential 2 & $c f=1-\exp (-a \Delta T)$ & 0.2341 & 0.395 & 0.477 & 0.351 & 0.484 & 0.421 \\
\hline Gaussian & $c f=a \exp \left[-\left(\frac{\Delta T-b}{c}\right)^{2}\right]$ & $0.9561,11.51,10.62$ & 0.479 & 0.507 & 0.388 & 0.539 & 0.457 \\
\hline
\end{tabular}

given the larger number of parameters; Table 7). This means that the regression models can explain a percentage variance in the computed daily cloud transmittance factors that ranges between $32.7 \%$ and $53.9 \%$, depending on the model. A noteworthy difference is that the exponential functions yield lower cloud transmittance factor values at small $\Delta T\left(1-3^{\circ} \mathrm{C}\right)$. This might be a limitation of this specific function, and other functions such as the Gaussian might be best suited to reproduce outcomes at the limits of the range if such values are important.

Since no simple curve can replicate all the variability displayed by the daily cloud transmittance factors, we analyzed the errors of the regression models. Figure 9 shows the distribution of errors for the four case studies, where it is clear that parameterized cloud transmittance factors underestimate the measured cloud transmittance factors (the highest frequency of errors is between -0.1 and 0 ). From Figure 10 it is also clear that the underestimation occurs for high cloud transmittance factors (corresponding to clear-sky conditions) and this in turn results in an underestimation of incoming solar radiation on clear-sky days (in particular for Gorner 2005). This issue is discussed in more depth in section 4.5. This limitation, however, could be at least partly overcome by employing different functions for various temperature ranges through the use of stacked functions. It should also be noticed that the shape of the function and its ability to reproduce correctly high $c f$ is influenced by outliers, so they should be considered with care before performing the regression.

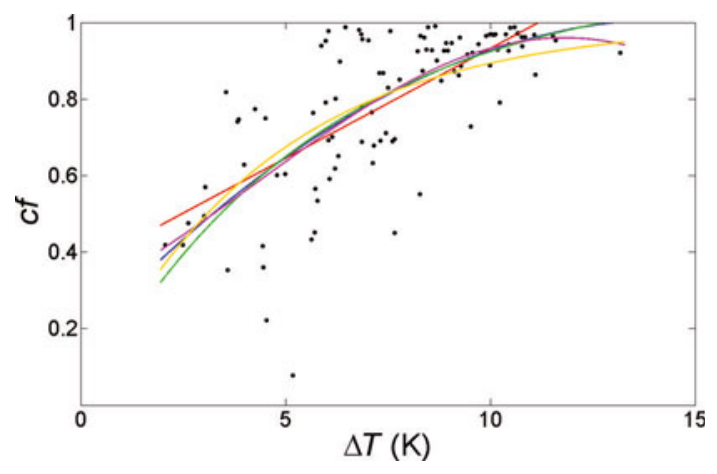

Fig. 8. Scatter plots of daily cloud transmittance factors of against daily temperature range for all four datasets pooled together. Also shown are the linear (red), polynomial (blue), Gaussian (pink) and exponential 1 and 2 (green and orange, respectively) regression functions that best fit the data.

\subsection{Influence of parameterizations on melt modelling}

In order to test the influence of the various parameterizations on modelled melt rate, we run the ETI model (Equation (19)) with the parameterizations described above for the Arolla 2006 (26 May to 30 September) and Gorner 2005 (4 June to 15 September) datasets. We implemented the linear and exponential 2 parameterization of Table 7, given that differences between all parameterizations are small and that these require only one or two coefficients. We applied both parameterizations with: (1) the parameters optimized for the single location; (2) the mean parameters for the four test sites (Table 7); and finally (3) the parameters calibrated by Pellicciotti and others (2005). We also report results of melt simulations with measured incoming shortwave radiation, which correspond to the best model performance. As in Pellicciotti and others (2005), we use energy-balance simulations as reference melt (Pellicciotti and others, 2008; Carenzo and others, 2009) and use the Nash and Sutcliffe (1970) $R^{2}$ to evaluate the model performance.

Table 8 lists the $R^{2}$ for hourly melt computed for the entire season with the ETI model forced by measured incoming solar radiation and by the ETI model with the exponential 2 and linear parameterizations. The main result is that there is hardly any difference in model performance associated with varying parameterization or parameters set. The ETI model performance decreases (from 0.943 and 0.935 to values in

Table 8. Nash and Sutcliffe's (1970) efficiency criterion $R^{2}$ for hourly melt simulated with the ETI model including different forms of the cloud transmittance factor parameterizations. The $R^{2}$ is calculated against reference simulations obtained from an energybalance model (see text). Model $\mathrm{D}$ is the model run with measured incoming shortwave radiation. In parentheses are the $R^{2}$ values obtained by assuming $c f=1$ for $c f$ outcomes $\geq 0.8$, which defines the threshold for clear-sky conditions (see section 5) for the linear and exponential model

\begin{tabular}{lcc}
\hline Model version & Arolla 2006 & Gorner 2005 \\
\hline Model D & 0.943 & 0.935 \\
Model E original & 0.815 & 0.721 \\
Model E linear & $0.821(0.834)$ & $0.765(0.791)$ \\
Model E linear mean & 0.824 & 0.765 \\
Model E exponential & $0.819(0.828)$ & $0.761(0.791)$ \\
Model E exponential & 0.822 & 0.765 \\
mean & &
\end{tabular}



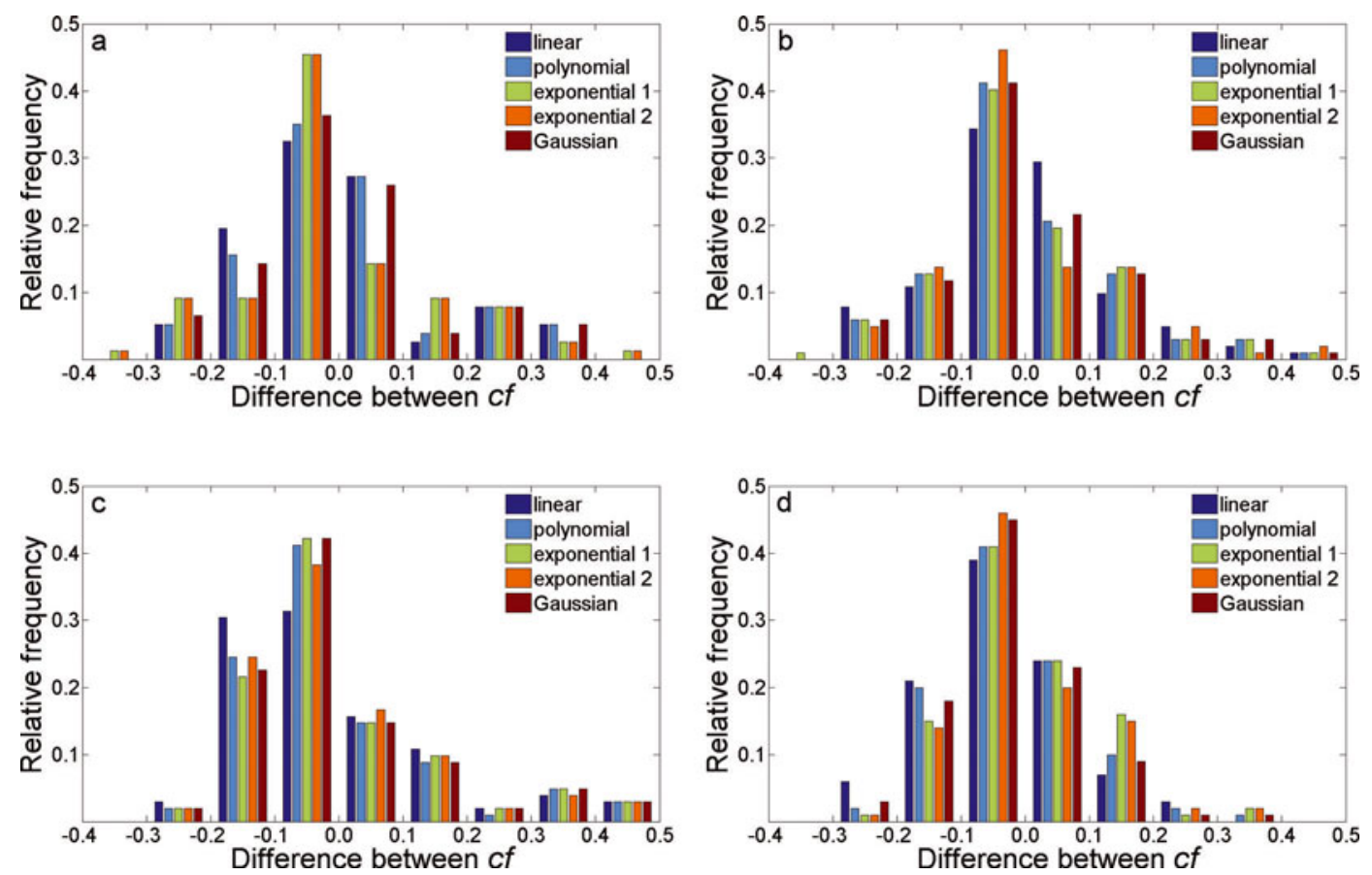

Fig. 9. Distribution of errors between 'measured' (i.e. computed from measurements of incoming solar radiation) and parameterized cloud transmittance factors at (a) Arolla 2001, (b) Arolla 2006, (c) Gorner 2005 and (d) Gorner 2006. Differences are computed as parameterized minus measured cloud transmittance factor.

the range $0.815-0.824$ and $0.721-0.765$ for Arolla 2006 and Gorner 2005, respectively) when modelled incoming shortwave radiation and parameterized cloud transmittance factors are used for melt computation, depending on the parameterization. The decrease is stronger for Gornergletscher 2005, with the lowest model performance associated for both sites with the original parameters of Pellicciotti and others (2005).
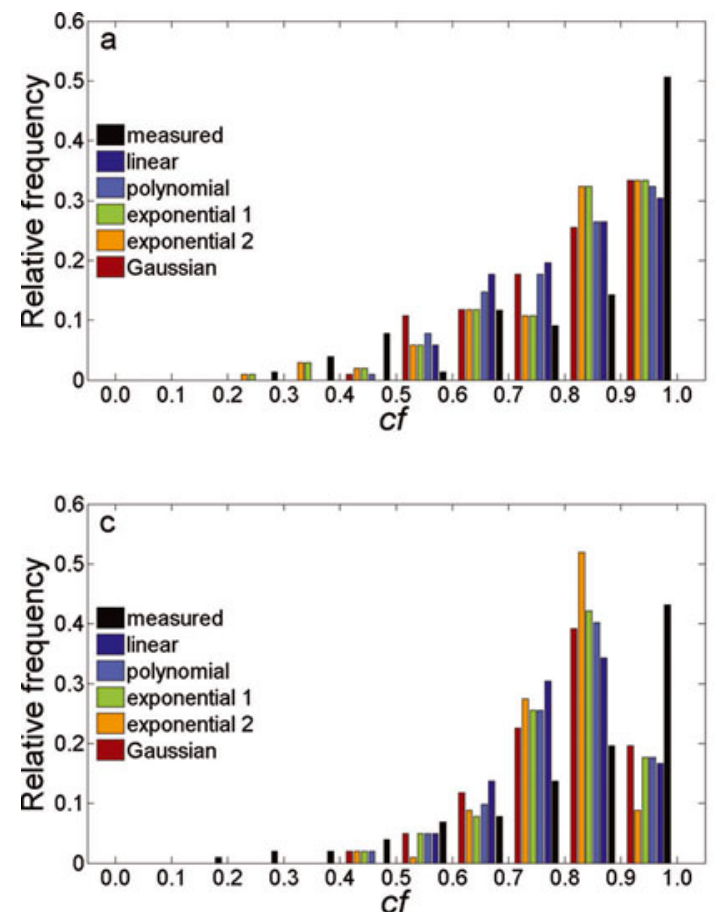

The decrease in model performance indicated by the $R^{2}$ is due to the underestimation of hourly melt rates by the ETI model on clear-sky days, especially in the hours around noon (Fig. 11). Interestingly enough, the model works very well on overcast days such as 16, 17 and 23 June 2006 (Fig. 11) when agreement with the energy-balance model is very good. This is despite the fact that the model cannot reproduce the sub-daily variations due to passing clouds
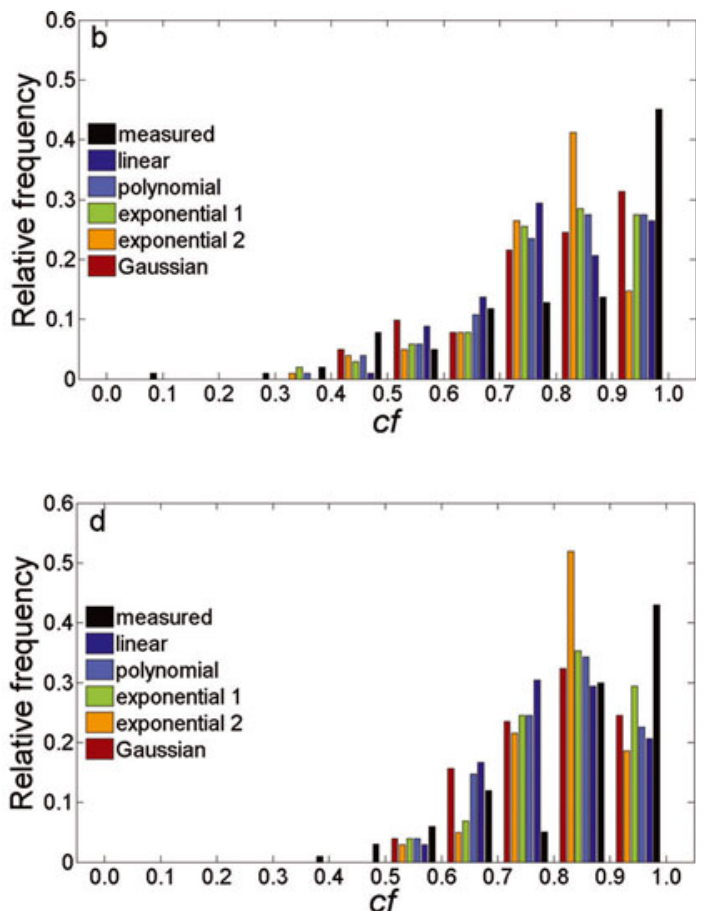

Fig. 10. Distribution of cloud transmittance factors: measured (i.e. computed from measured and modelled shortwave radiation) and parameterized with five different regression functions (linear, polynomial, Gaussian and exponential 1 and 2) at (a) Arolla 2001, (b) Arolla 2006, (c) Gorner 2005 and (d) Gorner 2006. 
(e.g. on 16 and 17 June). The underestimation of hourly melt rates on clear-sky days leads to an underestimation of total melt ranging between $7 \%$ and $13 \%$ of total energy-balance ablation (Table 9 ) and between $2 \%$ and $7 \%$ of total model D (ETI model with measured incoming shortwave radiation) melt for Arolla 2006. Values are higher for Gorner 2005 despite the fact that agreement between energy balance and model $\mathrm{D}$ total melt is almost perfect, and higher than on Arolla 2006 (0.9\% compared to $-7.2 \%)$. If the ETI model is run with the cloud transmittance factors from the regression functions, however, the difference from the reference melt rates is higher (Table 9).

Assessment of the impact of the cloud parameterization on the performance of the temperature-index melt model has to take into account the fact that the ETI model slightly underestimates hourly ablation rates (Pellicciotti and others, 2005). The ETI model empirical parameters have not been recalibrated for the single sites and seasons, which explains some of the difference between the ETI and measured data and the energy-balance model.

\subsection{Modelling incoming shortwave radiation and melt using COSMO}

Output from weather prediction models offers an alternative to the approach described above in two ways. We can use simulations of hourly air temperature to derive the daily temperature range used in regression analysis to predict the daily cloud transmittance factor (similar to the approach based on in situ air-temperature observations) or we can use incoming shortwave radiation simulated by the climate model directly into the melt model. Both outputs are for a gridcell of $2.2 \mathrm{~km}$ resolution, i.e. encompassing the whole of Arolla.

We have tried both approaches in our search for an alternative to the method explored at length in this paper. We first applied COSMO gridded air temperature to derive a time series of daily temperature range and then regressed this against computed daily cloud transmittance factor. The main result is that there is no clear advantage in using air temperature from the regional climate model (but also no clear disadvantage). We obtain the same type of functional relationship between the dependent variable daily cloud transmittance factor and the independent variables $\Delta T$ and $\mathrm{RH}$. Maximum, mean and minimum temperature alone, wind speed or precipitation do not show any clear

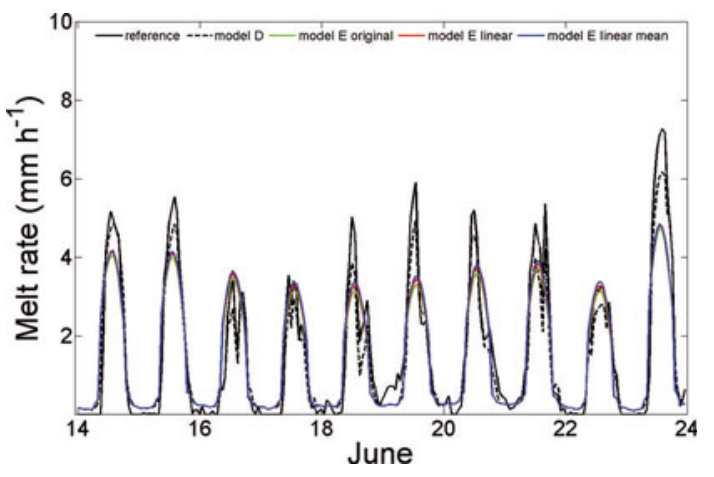

Fig. 11. Hourly melt rates computed with the energy-balance model (reference), the ETI model with measured input data and the ETI model with various forms of the cloud transmittance factor parameterization (see text) for the period 14-24 June 2006 on Arolla lowest station. Notice the cloudy days on 16, 17 and 23 June.

relationship to the air-temperature range, as was evident for the in situ ground measurements.

The strength of the regression (for both types of regression equation) with temperature range is lower for COSMO data as compared to the ground measurements (with coefficients of determination ranging from 0.247 to 0.326 ), and results in a slightly lower predictive ability. Minimum relative humidity is, after the air-temperature range, the best predictor of variations in the daily cloud transmittance factor. In this case, however, the regression function explains a lower percentage of the variability in the cloud transmittance factor than do the ground data.

The second way in which the outputs of the regional model can offer an alternative to the cloud transmittance factor parameterization based on ground measurements is to directly use the incoming shortwave radiation simulated by COSMO as input to the ETI model. We tried this and found that the $R^{2}$ is higher than when modelled clear-sky solar radiation is used in combination with parameterizations of the cloud transmittance factor (whether based on ground temperature measurements or COSMO temperature outputs). Total melt at the end of the season also shows much better agreement with the energy-balance reference total melt, with $<1 \%$ difference. This good performance, however, is due to a compensation of errors, as is clear from

Table 9. Total melt simulated by the energy-balance model (reference melt), the ETI model with measured incoming shortwave radiation (model D) and the ETI model with various forms of the cloud transmittance factor parameterization (see text). Mean indicates that the mean values of the regression function parameters are used

\begin{tabular}{|c|c|c|c|c|c|c|}
\hline \multirow[t]{3}{*}{ Model version } & \multicolumn{3}{|c|}{ Arolla 2006} & \multicolumn{3}{|c|}{ Gorner 2005} \\
\hline & Total melt & $\begin{array}{c}\text { Difference } \\
\text { from reference }\end{array}$ & $\begin{array}{c}\text { Difference } \\
\text { from model D }\end{array}$ & Total melt & $\begin{array}{c}\text { Difference } \\
\text { from reference }\end{array}$ & $\begin{array}{c}\text { Difference } \\
\text { from model D }\end{array}$ \\
\hline & mm w.e. & $\%$ & $\%$ & mm w.e. & $\%$ & $\%$ \\
\hline Energy-balance & 4386 & & & 4351 & & \\
\hline Model E original & 3797 & -13 & -7 & 3699 & -15 & -16 \\
\hline Model E linear & 3916 & -11 & -4 & 3863 & -11 & -12 \\
\hline Model E linear mean & 3989 & -9 & -2 & 3881 & -11 & -12 \\
\hline Model E exponential & 3909 & -11 & -4 & 3851 & -11 & -12 \\
\hline Model E exponential mean & 3973 & -9 & -2 & 3902 & -10 & -11 \\
\hline
\end{tabular}




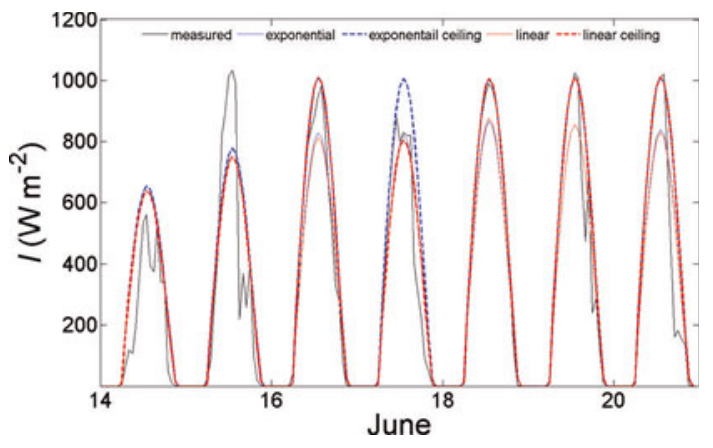

Fig. 12. Hourly incoming shortwave radiation measured at the glacier AWS on Gornergletscher for the period 14-20 June 2005, and simulated by the radiation model with and without the $c f$ threshold of 0.8 for clear-sky conditions for the linear and exponential 2 parameterizations with parameters optimized for the two sites.

comparison of measured and COSMO incoming shortwave radiation (Fig. 2): solar radiation simulated by COSMO overestimates measured incoming radiation by on average about $50 \mathrm{~W} \mathrm{~m}^{-2}$.

\section{DISCUSSION}

A regression model of linear or exponential shape can explain between about $33 \%$ and $54 \%$ of the variance in the computed cloud transmittance factors. From looking at the relationship between cloud transmittance factors and temperature range (Fig. 7), there seem to be two problems explaining the limited predictive ability of the regression models: firstly, the presence of larger scatter in the relationship for low values of $\Delta T$ and $c f$ (Fig. 7) and secondly, the underestimation of high cloud transmittance factors by the parameterizations (Fig. 8), which seems to be independent of the type of function (Figs 9 and 10).

As far as the scatter is concerned, some of the points seem to be outliers (especially in the case of Gorner 2005; Fig. 7c) and it could prove useful to understand which synoptic conditions and weather type they are associated with. We did not have this information, however; this issue may be investigated in future studies. To address the second point, we have defined a larger range for clear-sky conditions. Anslow and others (2008) suggested that cloud transmittance factors of $\geq 0.8$ represent completely clear skies. Following this, we set $c f \geq 0.8$ equal to 1 , and rerun simulations for both Arolla 2006 and Gorner 2005.

Figure 12 shows incoming shortwave radiation measured at the AWS on Gornergletscher and simulated by the solar radiation model using cloud transmittance factors computed as described above and assuming clear skies for $c f \geq 0.8$. The latter assumption leads to a clear improvement in the model simulations. The effect is not noticed for overcast conditions (for which the parameterization worked well) but was evident on clear-sky days such as 18 June. For completely clear-sky days (such as 18 June), modelled and measured parameterization match perfectly. Discrepancies are still evident on days with only partial cloud cover (normally limited to a few hours in the afternoon), such as 19 and 20 June, and are due to the fact that the cloud transmittance factor is daily and cannot account for the subdaily variability in incoming shortwave radiation associated with passing clouds. This explains why the $R^{2}$ computed between measured and modelled radiation with the new calculations do not indicate perfect agreement (varying between 0.819 and 0.836 ). Peak values during the middle part of the day, however, are now reproduced very well.

It is evident from Figure 12 that differences in the regression functions only have a very minor impact on incoming solar radiation (and therefore melt), as already evident from the analysis above (a difference between simulations with the exponential and linear regression model can only be observed on 17 June). Simulations of melt rates also improve as a result, reducing the constant underestimation observed for clear-sky conditions (Table 8).

From this analysis it seems important to correctly identify clear-sky conditions, since a small readjustment to their definition has brought an important improvement in the model performance. We therefore suggest that this modified computation should be used. Furthermore, the threshold of 0.8 seems to be valid for various conditions at mid-latitudes, since it was originally suggested by Anslow and others (2008) for South Cascade Glacier. However, while the threshold and correct definition of overcast conditions is important, it might at least partly correct for the underestimation of the parameterized cloud transmittance factors discussed in section 4.4. Use of different functions for different temperature ranges, and of a different function for high $\Delta T$ in particular, might offer an improvement to this.

More complex models which take into account cloud properties, as well as the cloud amount, may be able to explain the increased variability. Our approach does not include cloud properties such as cloud depth and height, the amount and phase of condensed water, the size and shape of the condensed particles and the optical properties that depend on these characteristics. These are generally poorly known (especially in mountainous areas), and more research and collection of data could be devoted to increase our understanding of the way cloud properties modulate the incoming shortwave radiation flux over glacierized areas.

Our work has shown that there is no substantial difference between various parameter sets. To prove this point further, we have investigated the solar radiation model sensitivity to systematic changes in the regression function parameters from $10 \%$ to $100 \%$. We obtain two main findings. Firstly, the linear model is more sensitive to changes in the intercept (parameter a of Equation (18)) than to changes in the slope parameter $b$. Secondly, the exponential model is more sensitive to changes in the parameter than the linear model. For this reason, we suggest that the linear model could be used despite the fact that a linear relationship alone does not explain all the variability observed in the cloud-cover variable and it does not recognize the $U$-shape nature of cloud transmittance factor distributions.

Using cloud transmittance factors computed from the COSMO daily temperature range results in a decrease in the model's ability to correctly simulate both the incoming shortwave radiation and melt rates compared to using ground station data. Alternatively, using COSMO incoming shortwave radiation directly in the melt model works well, but for the wrong reasons.

We have not used outputs from regional climate models (RCMs) because of the larger grid size (tens of kilometres compared to a few kilometres). We can reasonably assume, however, that the characterization of clouds in RCMs will not be much better than in an atmospheric model such as 
COSMO, and conclude that both types of approach do not offer a suitable alternative to the use of in situ ground data at a model resolution of $>2 \mathrm{~km}$. They could, however, be useful for mountain regions where data are more scarce, so that comparison of their deviation from ground observations might be useful to determine the level of uncertainty in melt and mass-balance models that use such approaches (Machguth and others, 2009). A reasonable alternative might be provided by satellite data, including the International Satellite Clouds Climatology Project (ISCCP; Rossow and others, 2002).

\section{SUMMARY AND CONCLUSIONS}

We have explored the relationship between clouds and the surface radiative fluxes with particular attention to the impact of cloud radiative forcing on the shortwave radiation balance, given its crucial importance in models of snow and ice ablation. We have addressed this issue in the context of glacier ablation modelling, since clouds have been recognized as one key factor affecting the surface energy budget of glaciers and snow covers at the surface-atmosphere interface (Curry and others, 1993; Zhang and others, 1996; Shupe and Intrieri, 2004; Van den Broeke and others, 2006; Giesen and others, 2008). As such, uncertainties in their influence which is complex and not yet completely understood (Shupe and Intrieri, 2004; Gorodetskaya and others, 2008) - has been identified as a major source of uncertainty in the prediction of changes in the ice and snow surface energy balance (e.g. the Arctic surface (Shupe and Intrieri, 2004)).

We used an approach based on computation of cloud transmittance factors, i.e. a variable representing the cloud radiative forcing that has been used in point energy-balance studies (Fitzpatrick and Warren, 2005). This approach is taken a step further by examining the relationship of such a transmittance variable with meteorological variables measured in situ at AWSs on- and off-glacier, in order to establish a parameterization of cloud cover that can be used when detailed radiation measurements or information on cloud properties are not available (especially for grid-based, distributed models of glacier melt).

Several attempts have been made to link the atmospheric transmittance associated with clouds and their forcing on the surface radiation balance to parameters commonly available such as diurnal temperature range (Bristow and Campbell, 1984; Thornton and Running, 1999). This, however, has only rarely been attempted for snow and ice surfaces. The cloud transmittance factor parameterization by Pellicciotti and others (2005) was developed for one site and season. We therefore tested such an approach for several other glacier sites where detailed observations of the meteorological forcing were available over several seasons and accurate DEMs allowed calculations of clear-sky solar radiation irradiance. We tested the robustness of the regression model parameters, and their transferability across seasons and sites, and sought alternative ways of modelling the cloud-cover variable.

The main results of our work are as follows:

1. The original cloud transmittance factor parameterization proposed by Pellicciotti and others (2005) is robust when tested across a range of sites and seasons in the climatic setting of the southern Alps of Switzerland. Recalibration of model parameters does not lead to major improvement in model performance, which was assessed both against measured solar radiation and against hourly and total melt rates simulated by an energy-balance model.

2. The percentage variance explained by the regression functions lies in the range $30-50 \%$ depending on the function. Our analysis has confirmed the finding by Pellicciotti and others (2005) that the diurnal temperature range is the best predictor of cloud transmittance variability.

3. The choice of the regression equation does not have a major impact on the model performance, even though different equations might have a larger or smaller number of parameters.

4. Parameterizations of cloud transmittance factor work well for cloudy days, but degrade the model performance on clear-sky days. This is independent of the specific regression or parameter set, and seems to be due not so much to the amount of variability in cloud transmittance factors that can be expressed by changes in the diurnal temperature range but rather to the uncertainty arising from the specification of clear-sky conditions.

5. If we define the cloud transmittance factors corresponding to clear-sky conditions in a larger way, we obtain a clear improvement in model performance. In particular, by assuming that clear-sky conditions are represented by cloud transmittance factors of $>0.8$ (Anslow and others, 2008), an improvement in simulation of both incoming solar radiation and melt rates is evident.

6. The calculation of cloud transmittance factors, as pointed out already by Klok and others (2005) and Mölg and others (2009), is prone to errors due to even small differences between modelled and measured incoming shortwave radiation. These are likely to occur in the early and late hours of the day corresponding to low zenith angle. We suggest that weighted daily cloud transmittance factors should be used instead, to at least partly compensate for such errors.

7. Solar-radiation, cloud-cover and air-temperature outputs from mesoscale atmospheric models did not provide an alternative to our approach based on in situ observations of air temperature. The functional relationship between cloud transmittance factors and modelled $2 \mathrm{~m}$ COSMO air temperature is similar to that between cloud factors and measured air temperature, showing that the two temperature time series are correlated. In both cases, scatter is higher for low temperature ranges.

8. We have also tested in detail the clear-sky parametric solar radiation model and shown that, despite its high accuracy at the point scale, errors can be caused by inaccuracies in the DEM and inaccurate values of slope and aspect. This is a component of the surface energy balance that, despite being of key importance in the energy budget, is rarely tested individually.

By using several datasets, we have explored in detail the applicability of a cloud-cover parameterization that predicts the cloud transmissivity based on variations in the daily temperature range. The parameterization probably has potential to improve in response to advances in understanding of the relationship between cloud radiative forcing 
and changes in air temperature and other meteorological variables routinely measured at AWSs. However, it does not take into account any of the microphysical characteristics such as optical thickness, liquid water content or particle size distribution that attenuate radiation. Parameterizations of the type suggested by Fitzpatrick and others (2004) are useful, but require data that are generally not often available (in particular at mountainous sites). Satellite data might provide useful alternative datasets for inclusion of the cloud forcing in energy-balance models of glacier ablation.

This work has explored parameterizations of summer cloud cover as a crucial component of the summer glacier energy balance. It was not possible to study the dependency of the cloud radiative forcing for the whole year because of the lack of incoming shortwave radiation measurements on glaciers during winter. It might be interesting to investigate such relationships for winter datasets in the future, however, which are likely to have a different transmittance from that of ablation seasons as Bristow and Campbell (1984) have pointed out.

\section{ACKNOWLEDGEMENTS}

We thank A. Bauder and A. Kretz (VAW, Zürich) for the Gornergletscher data. Thanks are due to D. Lounberger of the Federal Office of Meteorology and Climatology MeteoSwiss for providing the COSMO data. The comments of two anonymous reviewers improved the manuscript and are gratefully acknowledged. Thanks also to editor R. Hock for her comments.

\section{REFERENCES}

Anslow, F.S., S. Hostetler, W.R. Bidlake and P.U. Clark. 2008. Distributed energy balance modeling of South Cascade Glacier, Washington and assessment of model uncertainty. J. Geophys. Res., 113(F2), F02019. (10.1029/2007JF000850.)

Arnold, N.S., I.C. Willis, M.J. Sharp, K.S. Richards and W.J. Lawson. 1996. A distributed surface energy-balance model for a small valley glacier. I. Development and testing for Haut Glacier d'Arolla, Valais, Switzerland. J. Glaciol., 42(140), 77-89.

Bintanja, R. 1996. The parameterization of shortwave and longwave radiative fluxes for use in zonally averaged climate models. J. Climate, 9(2), 439-454.

Bird, R.E. and R.L. Hulstrom. 1981. Simplified clear sky model for direct and diffuse insolation on horizontal surfaces. Golden, CO, Solar Energy Research Institute. Tech. Rep. SERI/TR-642-761.

Bristow, K.L. and G.S. Campbell. 1984. On the relationship between incoming solar radiation and daily maximum and minimum temperature. Agric. Forest Meteorol., 31(2), 159-166.

Campbell, G.G. and T.H. Vonder Haar. 1997. Comparison of surface temperature minimum and maximum and satellite measured cloudiness and radiation budget. J. Geophys. Res., 102(D14), 16,639-16,645.

Carenzo, M., F. Pellicciotti, S. Rimkus and P. Burlando. 2009. Assessing the transferability and robustness of an enhanced temperature-index glacier-melt model. J. Glaciol., 55(190), 258-274.

Corripio, J. 2003a. Modeling the energy balance of high altitude glacierised basins in the Central Andes. (PhD thesis, University of Edinburgh.)

Corripio, J.G. 2003b. Vectorial algebra algorithms for calculating terrain parameters from DEMs and solar radiation modelling in mountainous terrain. Int. J. Geogr. Inf. Sci., 17(1), 1-23.
Curry, J.A., J.L. Schramm and E.E. Ebert. 1993. Impact of clouds on the surface radiation balance of the Arctic Ocean. Meteorol. Atmos. Phys., 51(3-4), 197-217.

Dai, A., K.E. Trenberth and T.R. Karl. 1999. Effects of clouds, soil moisture, precipitation, and water vapor on diurnal temperature range. J. Climate, 12(8), 2451-2473.

Fitzpatrick, M.F. and S.G. Warren. 2005. Transmission of solar radiation by clouds over snow and ice surfaces. Part II: Cloud optical depth and shortwave radiative forcing from pyranometer measurements in the Southern Ocean. J. Climate, 18(22), 4637-4648.

Fitzpatrick, M.F., R.E. Brandt and S.G. Warren. 2004. Transmission of solar radiation by clouds over snow and ice surfaces: a parameterization in terms of optical depth, solar zenith angle, and surface albedo. J. Climate, 17(2), 266-275.

Frederick, J.E. and H.D. Steele. 1995. The transmission of sunlight through cloudy skies: an analysis based on standard meteorological information. J. Appl. Meteorol., 34(12), 2755-2761.

Garen, D.C. and D. Marks. 2005. Spatially distributed energy balance snowmelt modelling in a mountainous river basin: estimation of meteorological inputs and verification of model results. J. Hydrol., 315(1-4), 126-153.

Giesen, R.H., M.R. van den Broeke, J. Oerlemans and L.M. Andreassen. 2008. Surface energy balance in the ablation zone of Midtdalsbreen, a glacier in southern Norway: interannual variability and the effect of clouds. J. Geophys. Res., 113(D21), D21111. (10.1029/2008JD010390.)

Gorodetskaya, I.V., L.-B. Tremblay, B. Liepert, M.A. Cane and R.I. Cullather. 2008. The influence of cloud and surface properties on the Arctic Ocean shortwave radiation budget in coupled models. J. Climate, 21(5), 866-882.

Greuell, W. and R. Böhm. 1998. 2 m temperatures along melting mid-latitude glaciers, and implications for the sensitivity of the mass balance to variations in temperature. J. Glaciol., 44(146), 9-20.

Greuell, W. and C. Genthon. 2004. Modelling land ice surface mass balance. In Bamber, J.L. and A.J. Payne, eds. Mass balance of the cryosphere: observations and modelling of contemporary and future changes. Cambridge, Cambridge University Press, $117-168$

Greuell, W., W.H. Knap and P.C. Smeets. 1997. Elevational changes in meteorological variables along a mid-latitude glacier during summer. J. Geophys. Res., 102(D22), 25,941-25,954.

Hock, R. 2005. Glacier melt: a review on processes and their modelling. Progr. Phys. Geogr., 29(3), 362-391.

Iqbal, M. 1983. An introduction to solar radiation. New York, Academic Press.

Klok, E.J. and J. Oerlemans. 2002. Model study of the spatial distribution of the energy and mass balance of Morteratschgletscher, Switzerland. J. Glaciol., 48(163), 505-518.

Klok, E.J., M. Nolan and M.R. van den Broeke. 2005. Analysis of meteorological data and the surface energy balance of McCall Glacier, Alaska, USA. J. Glaciol., 51(174), 451-461.

Lowe, P.R. 1977. An approximating polynomial for the computation of saturation vapor pressure. J. Appl. Meteorol., 16(1), 100-103.

Machguth, H., F. Paul, S. Kotlarski and M. Hoelzle. 2009. Calculating distributed glacier mass balance for the Swiss Alps from regional climate model output: a methodical description and interpretation of the results. J. Geophys. Res., 114(D19), D19106. (10.1029/2009JD011775.)

Mölg, T., N.J. Cullen and G. Kaser. 2009. Solar radiation, cloudiness and longwave radiation over low-latitude glaciers: implications for mass-balance modelling. J. Glaciol., 55(190), 292-302.

Nash, J.E. and J.V. Sutcliffe. 1970. River flow forecasting through conceptual models. Part 1. A discussion of principles. J. Hydrol., 10(3), 282-290.

Niemelä, S., P. Raisanen and H. Savijärvi. 2001. Comparison of surface radiative flux parameterizations. Part II: shortwave radiation. Atmos. Res., 58(2), 141-154. 
Pellicciotti, F. 2004. Development of an ice and snow melt model for long term analysis of water resources from highly glacierised basins. (PhD thesis, ETHZ Zürich.)

Pellicciotti, F., B.W. Brock, U. Strasser, P. Burlando, M. Funk and J.G. Corripio. 2005. An enhanced temperature-index glacier melt model including shortwave radiation balance: development and testing for Haut Glacier d'Arolla, Switzerland. J. Glaciol., 51(175), 573-587.

Pellicciotti, F. and 7 others. 2008. A study of the energy balance and melt regime on Juncal Norte Glacier, semi-arid Andes of central Chile, using melt models of different complexity. Hydrol. Process., 22(19), 3980-3997.

Pellicciotti, F., M. Carenzo, J. Helbing, S. Rimkus and P. Burlando. 2009. On the role of the subsurface heat conduction in glacier energy-balance modelling. Ann. Glaciol., 50(50), 16-24.

Pfister, G., R.L. McKenzie, J.B. Liley, A. Thomas, B.W. Forgan and C.N. Long. 2003. Cloud coverage based on all-sky imaging and its impact on surface solar irradiance. J. Appl. Meteorol., 42(10), 1421-1434.

Prata, A.J. 1996. A new long-wave formula for estimating downward clear-sky radiation at the surface. Q. J. R. Meteorol. Soc., 122(533), 1127-1151.

Ritter, B. and J.F. Geleyn. 1992. A comprehensive radiation scheme for numerical weather prediction models with potential applications in climate simulations. Mon. Weather Rev., 120(2), 303-325.
Rossow, W.B., C. Delo and B. Cairns. 2002. Implications of the observed mesoscale variations of clouds for the earth's radiation budget. J. Climate, 15(6), 557-585.

Shupe, M.D. and J.M. Intrieri. 2004. Cloud radiative forcing of the Arctic surface: the influence of cloud properties, surface albedo, and solar zenith angle. J. Climate, 17(3), 616-628.

Sicart, J.E., P. Ribstein, P. Wagnon and D. Brunstein. 2001. Clear-sky albedo measurements on a sloping glacier surface: a case study in the Bolivian Andes. J. Geophys. Res., 106(D23), 31,729-31,738.

Tangborn, W.V. 1984. Prediction of glacier derived runoff for hydroelectric development. Geogr. Ann., Ser. A, 66A(3), 257-265.

Thornton, P.E. and S.W. Running. 1999. An improved algorithm for estimating incident daily solar radiation from measurements of temperature, humidity, and precipitation. Agric. Forest Meteorol., 93(4), 211-228.

Van den Broeke, M.R., D. van As, C.H. Reijmer and R.S.W. van de Wal. 2004. The surface radiation balance in Antarctica as measured with automatic weather stations. J. Geophys. Res., 109(D9), D09103. (10.1029/2003JD004394.)

Van den Broeke, M., C. Reijmer, D. van As and W. Boot. 2006. Daily cycle of the surface energy balance in Antarctica and the influence of clouds. Int. J. Climatol., 26(12), 1587-1605.

Zhang, T., K. Stamnes and S.A. Bowling. 1996. Impact of clouds on surface radiative fluxes and snowmelt in the Arctic and subarctic. J. Climate, 9(9), 2110-2123.

MS received 2 December 2009 and accepted in revised form 2 November 2010 